\title{
Isolation and Extraction of PHB from Soil Isolate: Determining its Physio- Chemical characteristics with an application study in Biomedical
}

\section{${ }^{1}$ Rejesh PC*, and ${ }^{2}$ Latha D}

${ }^{1}$ Research Scholar, Division of Microbiology, School of Biological Sciences, CMS College of Science and Commerce, Coimbatore, Tamil Nadu, India. +91-9846601280, rejechandran@yahoo.com

${ }^{2}$ Latha. D, Associate professor, Division of Microbiology, School of Biological Sciences, CMS College of Science and Commerce, Coimbatore-35, Tamil Nadu, India. +91-9486240862, lathagangolly@ rediffmail.com

*Corresponding author details;

${ }^{1}$ Research Scholar, Division of Microbiology, School of Biological Sciences, CMS College of Science and Commerce, Coimbatore, Tamil Nadu, India. rejechandran@yahoo.com 


\begin{abstract}
Biopolymer Poly Hydroxy Butyrate (PHB) is gaining importance based on its physiochemical and biological characteristics. Hence, the characteristics of the PHB extracted from soil bacterial isolate as studied with an aim of developing a 2D films for biomedical applications. The isolates from soil samples were screened for the ability to produce PHB and confirmed using Sudan black staining methods. The physio-chemical characteristics were studied using FTIR, FESEM and GCMS analysis. FTIR spectrum obtained for the extracted polymer shows peaks at $1723.51 \mathrm{~cm}^{-1}$ and $1287.63 \mathrm{~cm}^{-1}$ which confirms that the extracted polymer is PHB. FESEM image reveals the presence of pores of different size throughout the sample. The surface consists of multiple pores with different sizes. GC-MS analysis revealed the presence of various compounds attributing for the PHB production from the isolate. As a biological characteristic, a novel wound dressing 2D laminate biocomposite films were developed using PHB extracts. The antibacterial activity of the developed film showed significant inhibitory zones against Escherichia coli and Klebsiella pneumoniae. The present research work showed promising results and proved that the PHB obtained from bacterial sp. can be used as an alternative to non-degradable plastics with a wide range of applications in biomedical industries.
\end{abstract}

\title{
Keywords
}

Poly Hydroxy Butyrate, Biodegradable, Sudan Black, Wound Dressing film, Antibacterial activity 


\section{INTRODUCTION}

Plastics in the environment also mean uncontrolled problems due to plastic consumption, since they can persist in the environment for very long time (Ahmed et al., 2018). Many chemical compounds used in the plastics manufacturing as additives, in particular plasticizers are dangerous to human health and the environment (Singh and Rawat, 2019). Biodegradable plastics are the alternative offering the best solution to protect the environment from hazards caused by conventional petroleum based plastics as they are 'ecofriendly' in nature (Giin-Yu et al., 2014). Among them polyhydroxybutyrate (PHBs) are the only $100 \%$ biodegradable ones. PHBs are macromolecules synthesized by bacteria and are inclusion bodies accumulated as reserve material when the bacteria grow under different stress conditions (Galia, 2010). The process of the production of bioplastics from microbes has been optimised with a range of end products having widened up properties (Disha et al., 2012).

Polyhydroxy alkonate (PHA) are another type of biolpolymer produced by natural isolates and recombinant bacterial strain on different substrate along with the amount of PHA accumulated inside the bacterial cells (Kunasundari and Sudesh, 2011). More than 250 different natural PHA-producers have been identified till date but, only a few have made it for the commercial biosynthesis including Alcaligenes latus, B. megaterium, C. necator and $P$. oleovorans, as they can utilize the easily available raw material as the carbon sources (Tanamool et al., 2013).

Biotechnological applications of PHB and PHA are recently gaining importance in the field of biomedical industries. They are used in clothing, industrial products, fluid containers, wrapping and building materials, packaging films, toys household, shopping and garbage bags (Jacquel, Nicolas et al., 2008). PHAs are applicable in coatings and medical temporary implants e.g. scaffolding for the regeneration of nerve axons and arteries ( $\mathrm{Su}$ et al., 2014 and Raşoga et al., 2017). Amphiphilic PHA copolymers have significant applications in drug delivery, tissue engineering and cardiovascular area, e.g., artery augments, vascular grafts, cardiologic stents, heart valves, implants, pericardial patches, microparticulate carriers, and dressing tablets (Romano et al., 2015; Pouton and Akhtar, 1998 and Olivera et al., 2001). PHAs are known to have various applications in packaging, medical, and disposal usage. PHA-based films have attracted interest for food packaging application due to its renewability, biodegradability, and water vapor barrier properties (Marcos et al., 2010). Antimicrobial active packaging is made by incorporating metal high-performance nanoparti- 
cles into PHA or PHB based polymer films (Emamifar et al., 2011).

Based on these properties of PHA and PHB, the physio-chemical and biological characteristics of biopolymer extracted from soil isolates were studied with an aim of developing a 2D wound dressing films using a bridging agent called glutraldehyde (GA) and a bio-binder, Poly vinyl alcohol (PVA). The physio-chemical studies like FTIR, FESEM and GCMS analysis was investigated to confirm the production of PHB; the biological antibacterial property of the developed films were determined against the wound causing bacterial species in the present research.

\section{MATERIALS AND METHODS}

\section{Isolation of PHB producing bacteria (Mikkili et al., 2014)}

Soil samples from different locations were collected in a sterile Petridish and brought to laboratory for isolation of PHB producing organisms. Around $1.0 \mathrm{~g}$ of sample was serially diluted in sterile distilled water and plated onto Basal Salt E2 agar medium [Media composition (g/l): ammonium sulfate; 2.5, glucose; 20, $\mathrm{K}_{2} \mathrm{HPO}_{4} ; 1.5, \mathrm{Na}_{2} \mathrm{HPO}_{4}$; 3.5, $\mathrm{MgSO}_{4} .7 \mathrm{H}_{2} \mathrm{O} ; 0.2$ and $1 \mathrm{ml}$ of trace element solution containing $1 \mathrm{mM}$ of $\mathrm{FeSO}_{4} .4 \mathrm{H}_{2} \mathrm{O}$, $\left.\mathrm{CaCl}_{2} \cdot 2 \mathrm{H}_{2} \mathrm{O}, \mathrm{MnSO}_{4} \cdot 4 \mathrm{H}_{2} \mathrm{O}, \mathrm{ZnCl}_{2}\right]$ supplemented with $1 \%$ glucose as substrate for PHB production. All the inoculated plates were incubated at $37^{\circ} \mathrm{C}$ for 24 to $48 \mathrm{~h}$. Following incubation various colonies of different morphologies including mucoid, branched and rhizoidal forms were individually picked from the plates and sub-cultured onto nutrient agar plates for Microscopic observations.

\section{Rapid screening of PHB producing organisms (Mikkili et al., 2014)}

Typical bacterial colonies with mucoid and rhizoidal structures were selected and subjected to perform Sudan Black B staining method. Onto a clean glass slide, two drops of sterile water was placed and the colonies of selected bacterial isolates were transferred onto it. Thin smear was prepared with a gentle heat fixing intermediate step. About 5 drops of Sudan black B stains were added and left it for $5 \mathrm{~min}$ till the colour of the smear turns dark. The excess stain was washed off under running water and the counter stain saffranin was added to the smear. The slides were washed off after $3 \mathrm{~min}$ and dried under room temperature for $2 \mathrm{~min}$. All the slides were placed under microscopic observation to screen the PHB producing organisms. Black colour cells under 100X light microscopic magnification was considered as positive PHB producing organism; whereas negative organisms appear pink in colour. 
Production of polyhydroxybutyrate (PHB) from the selected isolate (Prabisha et al., 2015)

PHB producing organisms screened from Sudan Black B dye method was cultured in Basal Salt E2 medium. Each selected organisms was grown in $50 \mathrm{ml}$ aliquot of nutrient broth dispensed in $250 \mathrm{ml}$ Erlenmeyer flask and incubated at $37^{\circ} \mathrm{C}$ for $24 \mathrm{~h}$ at $150 \mathrm{rpm}$. About $1.5 \%$ inoculum of the overnight culture was used to inoculate Basal salts E2 medium [Media composition (g/l): ammonium sulfate; 2.5, glucose; 20, $\mathrm{K}_{2} \mathrm{HPO}_{4} ; 1.5$, $\mathrm{Na}_{2} \mathrm{HPO}_{4} ; 3.5, \mathrm{MgSO}_{4} .7 \mathrm{H}_{2} \mathrm{O} ; 0.2$ and $1 \mathrm{ml}$ of trace element solution containing $1 \mathrm{mM}$ of $\left.\mathrm{FeSO}_{4} .4 \mathrm{H}_{2} \mathrm{O}, \mathrm{CaCl}_{2} .2 \mathrm{H}_{2} \mathrm{O}, \mathrm{MnSO}_{4} .4 \mathrm{H}_{2} \mathrm{O}, \mathrm{ZnCl}_{2}\right]$ supplemented with $1 \%$ glucose. All the inoculated flasks were incubated at $37^{\circ} \mathrm{C}$ for 24 to $48 \mathrm{~h}$. At the end of incubation period, PHB was extracted and the quantity was determined.

\section{Extraction and quantification of PHB (Law and Slepecky, 1961)}

The best Sudan Black B positive bacterial isolates were subjected to quantification of PHB production by the method of Law and Slepecky, 1961. Cultures from the Basal salt E2 production medium after incubation period was collected in a sterile centrifuge tube and spin for $20 \mathrm{~min}$ at 10,000 rpm. The pellet was resuspended in equal volume of $4 \%$ sodium hypochlorite and incubated at $37^{\circ} \mathrm{C}$ for $30 \mathrm{~min}$. The pellet was washed with acetone, ethanol and water to remove the unwanted materials. The mixture was centrifuged again and the supernatant was discarded. Polymer granules obtained at the bottom of the tubes were dissolved in hot chloroform and allowed to evaporate. About $10 \mathrm{ml}$ of hot $\mathrm{H}_{2} \mathrm{SO}_{4}$ was added to the polymer granules to convert the polymer into crotonic acid which appears brown to black in colour. The solution was cooled and the absorbance at $235 \mathrm{~nm}$ was determined against a sulfuric acid blank. By referring to the standard curve, the quantity of PHB produced was determined.

Physio-Chemical and Biochemical characterization of PHB (Waala et al., 2017)

Different physiochemical and biochemical characteristics of PHB extracted from the isolate was studied separately using FTIR, GCMS and SEM analysis

\section{Field Emission Scanning Electron Microscopy (FESEM)}

PHB produced and extracted from the culture medium was partially purified and the sample was observed using Field-Emission Scanning Electron Microscopy (FESEM). The test materials were prepared for SEM using a suitable accelerating voltage (10 KV), vacuum (below $5 \mathrm{~Pa}$ ) and magnification (X 3500). Metal coating was used as the conducting material 
to analyse the sample.

\section{Fourier Transform Infra-Red spectroscopy (FTIR)}

The alteration in the functional groups of test materials was determined chemically using FTIR spectroscopy. The FTIR absorption spectra of PHB extracted from a selected isolate were recorded in the range of $400-4000 \mathrm{~cm}^{-1}$ by $\mathrm{KBr}$ disc method. FTIR spectra of the samples were determined using Shimadzu FTIR spectrophotometer. All the samples were prepared in $\mathrm{KBr}$ discs with a hydrostatic press at a force of $5.2 \tau \mathrm{cm}^{-2}$ for 3 minutes to reduce the moisture content on the disc surface. Each disc was dried under radiation to remove excess moisture content.

\section{Gas chromatograph - Mass Spectrometer (GC-MS)}

Gas Chromatography (GC) has been the method of choice for analysis of essential bioactive components of extracts from natural sources for many years. The bioactive components of PHB extracted from a selected isolate were investigated using a combination of GC technique with mass spectrometry (MS).

Gas chromatograph - Mass Spectrometer (Model- Shimadzu QP Model 5050A) equipped with fused silica capillary column $(30 \mathrm{~m} \times 0.25 \mathrm{~mm})$ and DB5 bonded phase $(0.25$ $\mathrm{mm}$ thick film) was used for analysis. The oven temperature was programmed at $40^{\circ} \mathrm{C}$ for 1 min, then raised to $250^{\circ} \mathrm{C}$ at $6^{\circ} \mathrm{C} / \mathrm{min}$ and held at this temperature for $4 \mathrm{~min}$. Helium as carrier gas at a flow rate of $1.0 \mathrm{ml}$ per min. The temperature was programmed at $50^{\circ} \mathrm{C}$ for $1.5 \mathrm{~min}$, followed by an increase of $4^{\circ} \mathrm{C}$ per min up to $200^{\circ} \mathrm{C}$, then at $10^{\circ} \mathrm{C}$ until reaching $250^{\circ} \mathrm{C}$ for $5 \mathrm{~min}$ [injector temperature: $250^{\circ} \mathrm{C}$ and detector temperature (or interface) $280^{\circ} \mathrm{C}$ ]. Injection volume $0.5 \mu 1$ was used with split ratio of $1: 25$. Each herbal extract was diluted in methanol at a concentration of $0.1 \mathrm{mg} / \mathrm{ml}$ and used for experimental study. The constituents were identified by comparison of their retention indices with literature values and their mass spectral data was measured by comparing Wiley mass spectral data value and from database indices of National Institute of Standards and Technology (Kovats, 1965).

PHB in medical applications - as wound dressing film (Joseph et al., 2019)

To enhance the wound dressing film formation, a bridging agent called glutraldehyde (GA) was used with the bio-binder (Poly vinyl alcohol). GA enhances the mechanical properties and bio-stability of developed wound dressing films.

About $2 \mathrm{~g}$ of extracted PHB was weighed separately in a precision balance kept in a 
sterile glass container. In a sterile polycarbonate petridish, $10 \mathrm{ml}$ of poly vinyl alcohol was added. GA was used in a concentration of $0.25 \%$ as a bridging agent. The pre-weighed PHB samples were added at a constant rate on the surface of PVA+GA mixtures. Care was taken to ensure whether the PHB samples were spread evenly on the surface of PVA+GA mixtures. The plates were kept in an orbital shaker (at 80rpm) to disperse PHB evenly. All the plates with added PHB samples were kept in an oven under the temperature set at $45^{\circ} \mathrm{C}$. The plates were dried till the mixtures get evaporated to form a final thin laminate film on the bottom surface of polycarbonate petridish. The developed packaging laminate films were carefully removed from the petridish surface and stored at $4^{\circ} \mathrm{C}$ for further analysis.

Antibacterial activity of developed wound dressing PHB films (Romanò et al., 2015)

To determine the antibacterial activity of developed wound dressing PHB films against the pyogenic organisms, modified Kirby-Bauer method was carried out. The antibacterial activity of wound dressing PHB films was evaluated against the five test organisms (Staphylococcus aureus, Enterobacter sp, Escherichia coli, Citrobacter sp., and Klebsiella pneumoniae) by disc diffusion method. Sterile Nutrient Agar (Composition g/L: Peptone: 5g; Yeast extract: 5g, Beef extract: 3g, Sodium chloride: 5g, Agar $15 \mathrm{~g}$; Final pH $(7.0 \pm 0.2)$ plates were prepared and allowed to solidify. About $0.1 \%$ inoculum suspensions of each of the bacterial cultures were swabbed with the sterile cotton swab three times by turning the plate at $60^{\circ}$ angle between each streaking. Under sterile conditions, film size of $20 \mathrm{~mm}$ in diameter was cut and placed on the agar surface of each Nutrient Agar (NA) plates. Filter paper disc impregnated with standard antibiotic solution (Gentamicin - 10 $\mu \mathrm{g} / \mathrm{ml}$ ) was also placed on the same plate to compare the efficacy of PHB films. All the plates were incubated at $37^{\circ} \mathrm{C}$ for $24-48 \mathrm{~h}$. The antibacterial activity was evaluated in terms of zone of inhibition around the wells of each extract in all the inoculated NA plates. The inhibition clear zones were measured and recorded in millimetre.

\section{RESULTS AND DISCUSSION}

\section{Isolation and rapid screening of native bacterial isolates for PHB production}

Microorganisms were isolated from rhizosphere soil sample and independent colonies were obtained by serial dilution (Fig. 1). A total of 10 bacterial colonies with different morphological features were selected and the numbers were given to each colony. These colonies were streaked on nutrient agar plates and preserved for further studies (Fig. 1A). Among 10 colonies, 5 colonies showed positive for Sudan Black B staining (Fig. 2). These 6 
colonies are 1, 2, 5, 6 and 7. They were named as strain 1, strain 2, strain 5, strain 6, strain and strain 7.

\section{Production, Extraction and quantification of PHB}

The PHB extracted from the selected bacteria were collected after centrifugation and stored in eppendorf tubes at $4^{\circ} \mathrm{C}$. Extraction of PHB from the six selected isolates was performed by sodium hypochlorite-chloroform method. Strain-1 produced $9 \mathrm{mg} / \mathrm{ml}$ of PHB. Strain- 2, 5 and 6 had produced $4 \mathrm{mg} / \mathrm{ml}, 22 \mathrm{mg} / \mathrm{ml}$, and $9 \mathrm{mg} / \mathrm{ml}$ of PHB respectively. About $6 \mathrm{mg} / \mathrm{ml}$ and $12 \mathrm{mg} / \mathrm{ml}$ of PHB were produced by strain-7 (Fig. 3).

\section{Physio-Chemical and Biochemical characterization of PHB}

Different physiochemical and biochemical characteristics of PHB studied separately using FTIR, GCMS and SEM analysis was discussed below.

\section{FESEM analysis of PHB}

Morphological characteristics of the PHB were examined using Field Emission Scanning Electron Microscopy (FE-SEM). Images obtained from scanning electron micrographs reveal the presence of pores of different size throughout the sample. The topographical images of the developed film were presented in Fig. 4.

\section{Fourier Transforms Infrared Spectroscopy (FTIR)}

Polymer extracted from the isolate was used for recording IR spectra in the range $4000-600 \mathrm{~cm}^{-1}$. IR spectra showed two intense absorption band at 1705 and $1034 \mathrm{~cm}^{-1}$, specific for $\mathrm{C}=\mathrm{O}$ and $\mathrm{C}-\mathrm{O}$ stretching vibrations, respectively. The absorption bands at 2916 and $2955 \mathrm{~cm}^{-1}$ are due to $\mathrm{C}-\mathrm{H}$ stretching vibrations of methyl, methylene groups. These prominent absorption bands confirm the structure of poly- $\beta$-hydroxybutyrate. FTIR spectrum obtained for the extracted polymer shows peaks at $1723.51 \mathrm{~cm}^{-1}$ and $1287.63 \mathrm{~cm}^{-1}$ which corresponds to specific rotations around carbon atoms specific to certain functional groups. The peak at $1723.51 \mathrm{~cm}^{-1}$ corresponds to $\mathrm{C}=\mathrm{O}$ (carbonyl) stretch of the ester group present in the molecule. The peak at $1287.63 \mathrm{~cm}^{-1}$ corresponds to $-\mathrm{CH}$ group. Absorption bands occurring at $2911.47 \mathrm{~cm}^{-1}$ and $2834.61^{-1}$ indicate the presence of aliphatic $-\mathrm{CH}_{3}$ and $-\mathrm{CH}_{2}$ groups. These peaks are similar to that obtained for the standard PHB (Sigma) at $1728 \mathrm{~cm}^{-1}$ and $1282 \mathrm{~cm}^{-1}$ confirming that the extracted polymer is $\mathrm{PHB}$ (Fig. 5). 


\section{GC-MS Analysis of Extracted PHB}

In this study, the PHB was methanolysed in the presence of sulphuric acid and methanol, and the methanolysed 3HB was then analyzed by GC-MS. Fig. 6 showed that a common molecular fragment of the $3 \mathrm{HB}$ methyl ester ion chromatogram of the PHB produced. A predominant peak corresponding to the $3 \mathrm{HB}$ methyl ester was noted at $2.1 \mathrm{~min}$, while four other small peaks were observed at 2.7,3.3, 3.5, and $3.8 \mathrm{~min}$. Of these, the peak at 3.3 min was speculated to be an impurity based on its ion fragment pattern. The retention times and ion fragment patterns of the peaks at 2.7 and 3.8 min were identical to those of the methyl esters of $3 \mathrm{HV}$ and $3 \mathrm{HHx}$, respectively. Nevertheless, the $3 \mathrm{HHx}$ content was negligible in this copolymer (less than $0.1 \mathrm{~mol} \%$ ). The peak at $3.5 \mathrm{~min}$ also had an ion fragment pattern similar to that of the $3 \mathrm{HHx}$ methyl ester; however, its retention time was not identical to that of 3HHx (Fig. 6).

\section{Antibacterial activity of developed PHB film}

Wound dressing 2D laminate biocomposite films using PHB extracted from the PHB producer was developed using a bio binder poly vinyl alcohol. Glutaraldehyde (GA) was used as a bridging agent. After drying the films were stored at $4^{\circ} \mathrm{C}$ for further analysis. Antibacterial activity of the developed film was investigated as follows.

The wound dressing film showed good antibacterial activity against all test organisms. Inhibitory zones of $22.6 \pm 0.57 \mathrm{~mm}, 21.3 \pm 1.04 \mathrm{~mm}, 23.2 \pm 0.25 \mathrm{~mm}, 20.6 \pm 0.57 \mathrm{~mm}$ and 19.1 $\pm 1.08 \mathrm{~mm}$ exhibited for respective organisms E. coli, S. aureus, Klebsiella pneumoniae, Citrobacter sp and Enterobacter sp (Table-1). The zone of clearance indicating the antibacterial activity of the extracted polymer was clearly evident in Fig. 7.

\section{CONCLUSION}

Microorganisms were isolated from rhizosphere soil sample and independent colonies were obtained by serial dilution. A total of 10 bacterial colonies with different morphological features were selected and the numbers were given to each colony. Among 10 colonies, 5 colonies showed positive for Sudan Black B staining. These 5 colonies are named as Strain-1, 2, 5, 6 and 7. Extraction of PHB from the six selected isolates was performed by sodium hypochlorite-chloroform method. FTIR spectrum obtained for the extracted polymer shows peaks at $1723.51 \mathrm{~cm}^{-1}$ and $1287.63 \mathrm{~cm}^{-1}$ which confirms that the extracted polymer is PHB. The obtained FE-SEM image reveals the presence of pores of different size throughout the sample. The surface consists of multiple pores with different sizes. GC-MS analysis of PHB 
showed the presence of various compounds like 1,2-Benzenedicarboxylic acid, 6methylheptyl 8-methylnonyl ester, isooctyl isodecyl phthalate, 1-(6-Methylheptyl) 2-(8methylnonyl) phthalate confirming the production of biopolymer from the isolate. Wound dressing 2D laminate biocomposite films using PHB extracted from the isolate was developed and its anti-bacterial activity was evaluated. Anti-bacterial analysis of the prepared wound dressing film showed significant inhibitory zones and maximum zone of inhibition against Escherichia coli and Klebsiella pneumoniae. The present research work showed promising results and proved that the PHB obtained from bacterial sp. can be used as an alternative to non-degradable plastics with a wide range of applications in biomedical industries. As a future perspective, the films shall also be considered for application in food industries to prevent the adherence and growth of aerobic microbes that could act as significant contaminant. The films shall be used as laminating or packaging materials of any type of food after undergoing optimization studies of the eco-friendly polymer extracted from the bacterial isolates.

\section{CONFLICT OF INTEREST}

Authors declare no conflict of interest in the present research

\section{REFERENCE}

- Ahmed T, Shahid M, Azeem F. Biodegradation of plastics: Current scenario and future prospects for environmental safety. Environ Sci Pollut Res Int. 2018; 25(8): 7287-7298.

- Disha N, Bhawana P, Fulekar MH. 2012. Production of biodegradable plastic from waste using microbial technology. Int J Res Chem Env. 2012; 2(2): 118-123.

- Emamifar A, Kadivar M, Shahedi M, Solaimanianzad S. Application of Antimicrobial Polymers Nanocomposites in Food Packaging, In: Adv Nanocomp Technol Food Cont. 2011; 22: 408-413.

- Galia MB. Isolation and analysis of storage compounds. In: Timmis KN, editor. Handbook of hydrocarbon and lipid microbiology. Berlin: Springer; 2010. p. 37253741.

- Giin-Yu AT, Chia-Lung C, Ling L, Liya G, Lin W. Start a research on biopolymer polyhydroxybutyrate (PHB). Polymers. 2014; 6:706-754.

- Jacquel N, Lo Chi-Wei, Wei Yu-Hong, Wu Ho-Shing, Shaw S. Isolation and purification of bacterial poly(3-hydroxyalkanoates). Biochem Eng J. 2008; 39 (1): 1527.

- Joseph B, Augustine R, Kalarikkal N, Thomas S, Seantier B and Grohens Y. Recent advances in electrospun polycaprolactone based scaffolds for wound healing and skin bioengineering applications. Mater Today Commun. 2019; 19:319-335. 
- Kunasundari B and Sudesh K (2011). Isolation and recovery of microbial polyhydroxyalkanoates. eXPRESS Polymer Letters, 5(7): 620-634.

- Marcos B, Aymerich T, Monfort JM, Garriga M. Physical performance of biodegradable films intended for antimicrobial food packaging. J Food Sci. 2010; 75(8): 502-507.

- Mikkili I, Karlapudi AP, Venkateswarulu TC. Isolation, screening and extraction of polyhydroxybutyrate (PHB) producing bacteria from sewage sample. International $\mathbf{J}$ Pharm Tech Res. 2014; 6(2): 850-857.

- Olivera ER, Carnicero D, Jodra R, Min ambres B, Garcia B, Abraham GA, Gallardo A, San Roma n J, Garcia JL, Naharro G. Genetically engineered Pseudomonas: a factory of new bioplastics with broad applications. Environ Microbiol. 2001; 3: 612618.

- Pouton CW, Akhtar S. Biosynthetic polyhydroxy alkanoates and their potential in drug delivery. Adv Drug Delivery Rev. 1996; 18(2): 133-162.

- Prabisha TP, Sindhu R, Binod P, Sankar V, Raghu KG, Pandey A. Production and characterization of PHB from a novel isolate Comamonas sp. from a dairy effluent sample and its application in cell culture. Biochem Eng J. 2015; 101: 150-159.

- Rasoga O, Sima L, Chiritoiu M, Popescu-Pelin G, Fufa O, Grumezescu O, Socol M, Stanculescu A, Zgura I, Socol G. Biocomposite coatings based on poly(3hydroxybutyrate-co-3-hydroxyvalerate)/calcium phosphates obtained by MAPLE for bone tissue engineering. Appl Surf Sci. 2017; 417: 204-212.

- Romano CL, Scarponi S, Gallazzi E, Romanò D, Drago L. Antibacterial coating of implants in orthopaedics and trauma: a classification proposal in an evolving panorama. J Orthop Surg Res. 2015; 10: 157-161.

- Singh S, Rawat PS. Biodegradation of Plastic: An Innovative Solution to Safe the Human Health and Environment. In: Handbook of Research on Environmental and Human Health Impacts of Plastic Pollution: Pennsylvania, USA: IGI Global; 2019: 435-461.

- $\quad$ Su Z, Li P, Wu B, Ma H, Wang Y, Liu G, Wei X. PHBVHHx scaffolds loaded with umbilical cord-derived mesenchymal stem cells or hepatocyte-like cells differentiated from these cells for liver tissue engineering. Mater Sci Eng C. 2014; 45: 374-382.

- Tanamool V, Imai T, Danvirutai P. Biopolymer generation from sweet sorghum juice: screening, isolation, identification, and fermentative polyhydroxy alkanoate production by Bacillus aryabhattai. Turk J Biol. 2013; 37: 259-264. 
Table-1: Qualitative Antibacterial activity of synergistic AMPs

\begin{tabular}{|c|c|c|c|c|c|}
\hline \multirow{2}{*}{ Sample } & \multicolumn{5}{|c|}{ Zone of inhibition (mm) } \\
\cline { 2 - 6 } & E. coli & S. aureus & K. & $\begin{array}{c}\text { S. } \\
\text { epidermidis }\end{array}$ & Enterobacter \\
& & & pneumoniae & $19.1 \pm 1.08$ \\
Wound & $22.6 \pm 0.57$ & $21.3 \pm$ & $23.2 \pm 0.25$ & $20.6 \pm 0.57$ & \\
\hline
\end{tabular}

All values calculated using mean \pm standard deviation 
Fig. 1: Isolates from serially diluted soil samples in nutrient agar

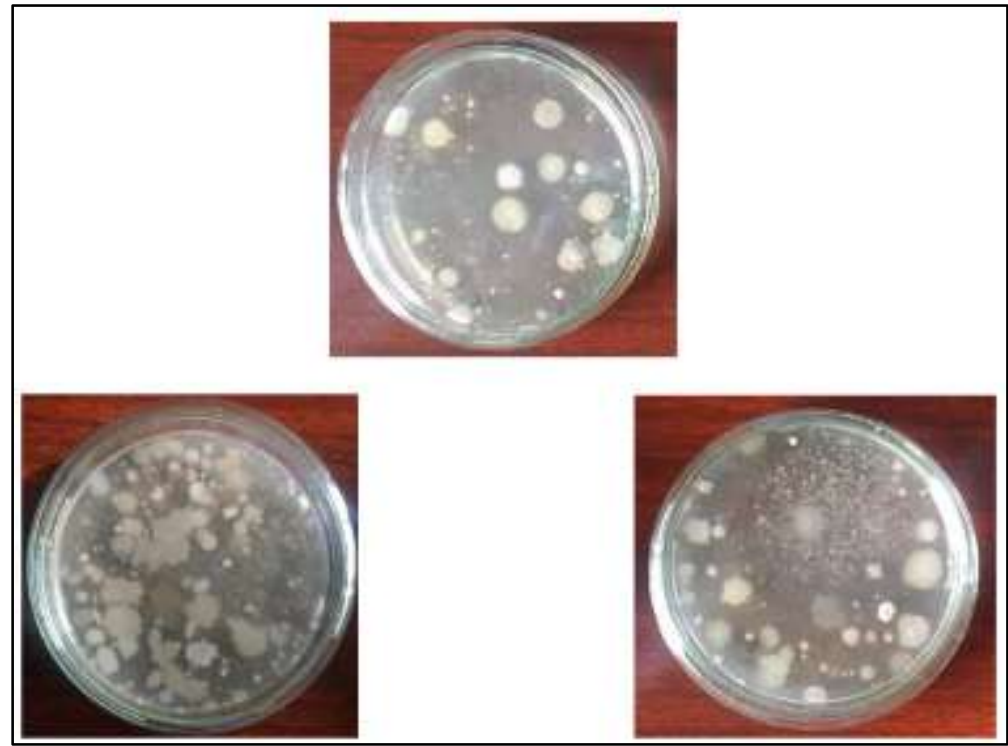

Fig. 1A: Preserved isolated colonies

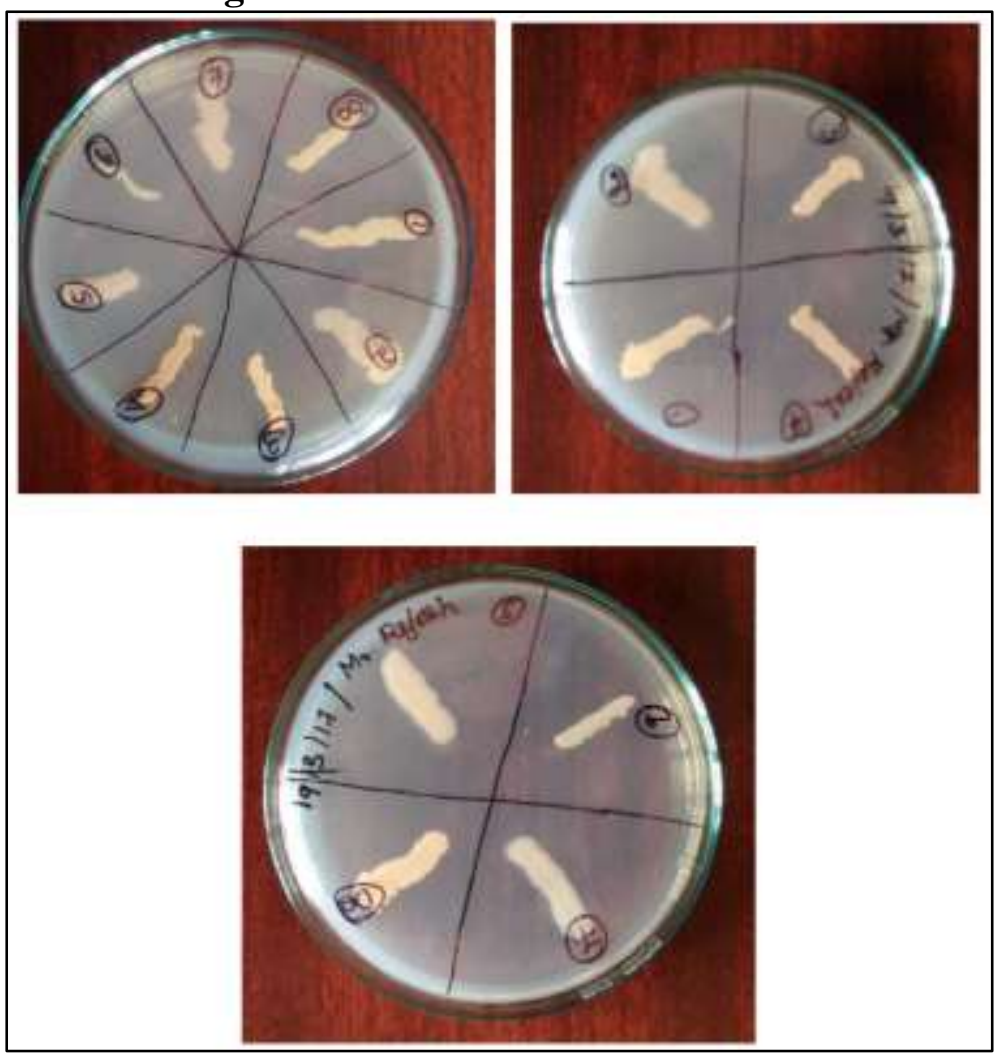


Fig. 2: Screening of PHB producers - Sudan Black Staining

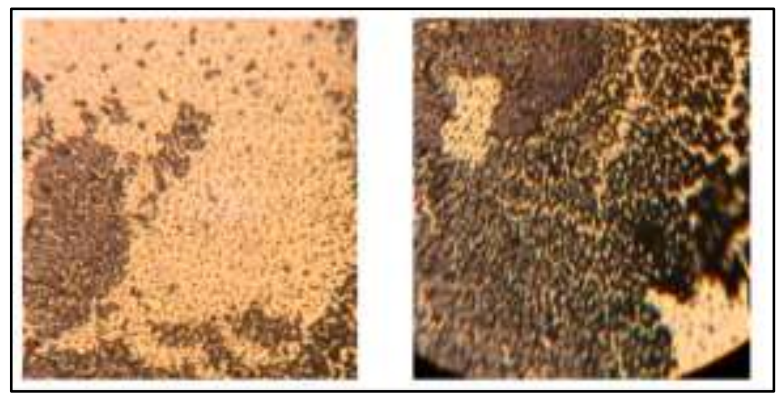

Strain - 1

Strain - 2

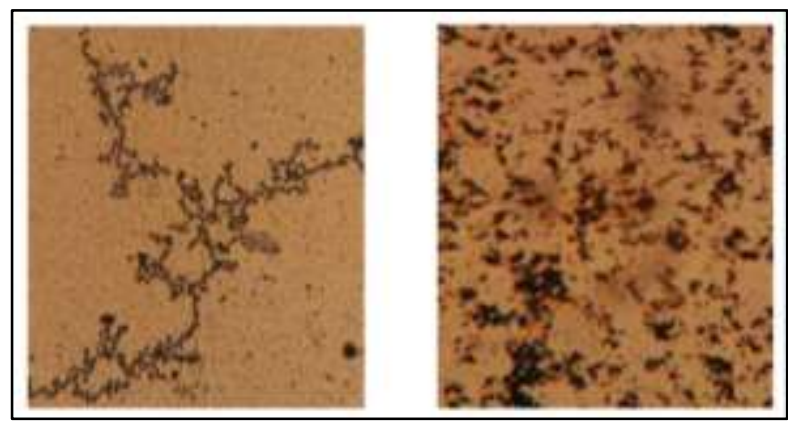

Strain - $5 \quad$ Strain - 6

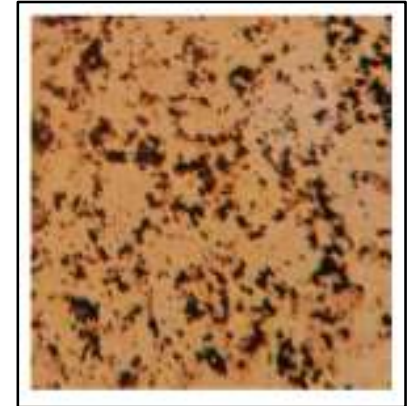

Strain - 7 
Figure-5: Extraction and Quantification of PHB from the isolate

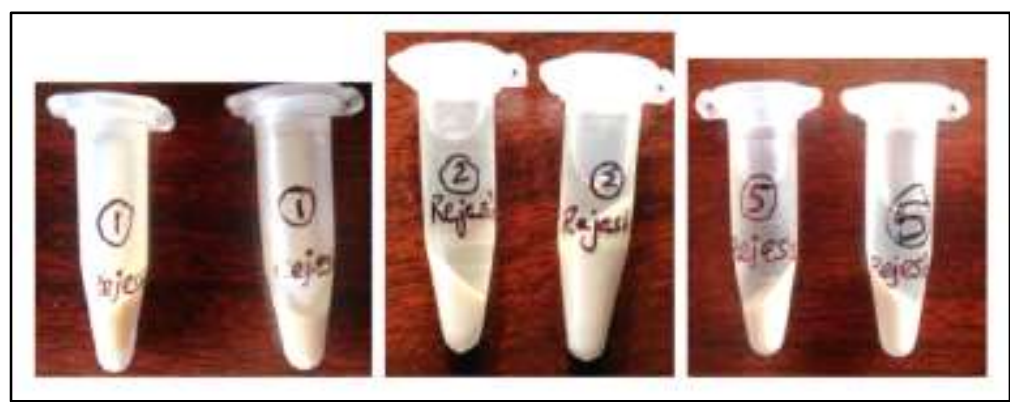

Strain - 1 Strain - 2 $\quad$ Strain - 5

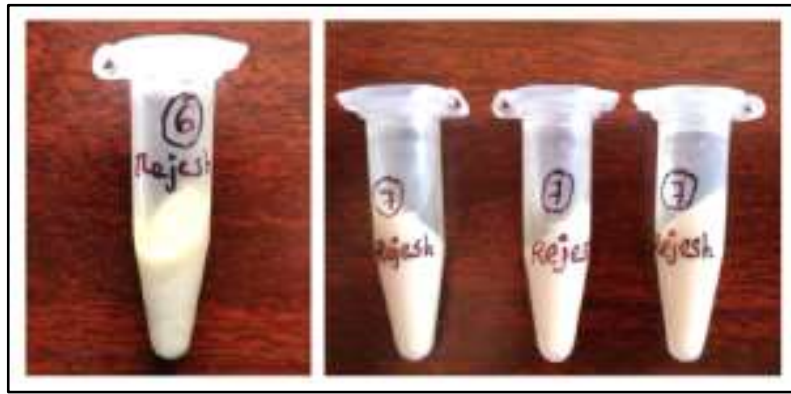

Strain - 6 Strain - 7

Fig. 4: Developed PHB film
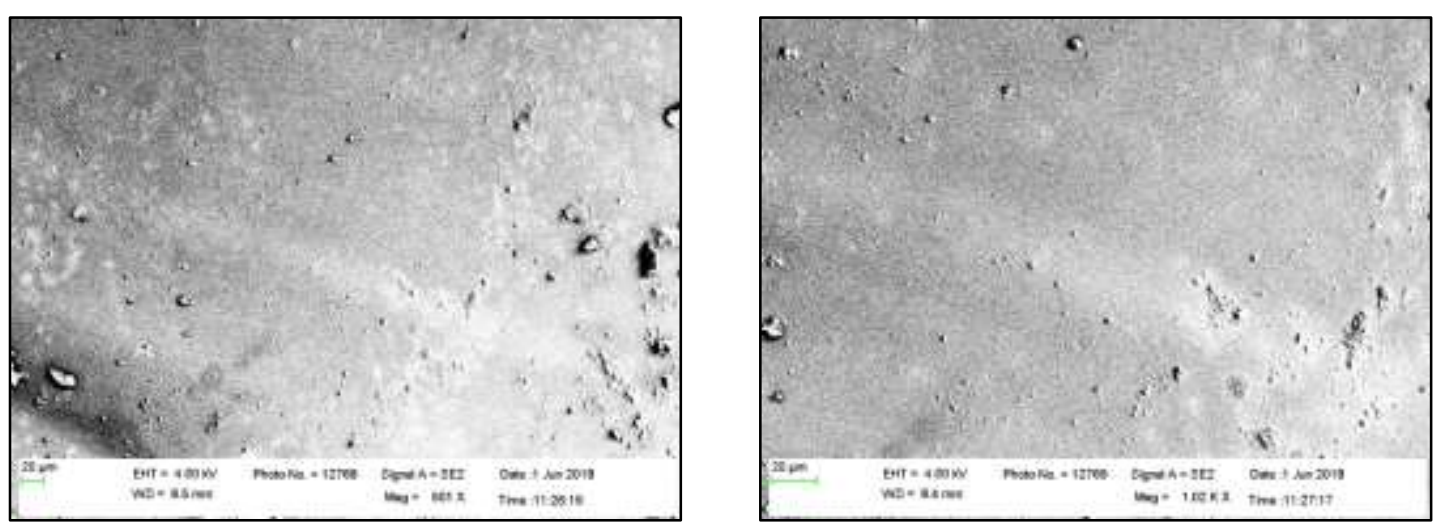
Fig. 5: Fourier Transforms Infrared Spectroscopy (FTIR) of PHB

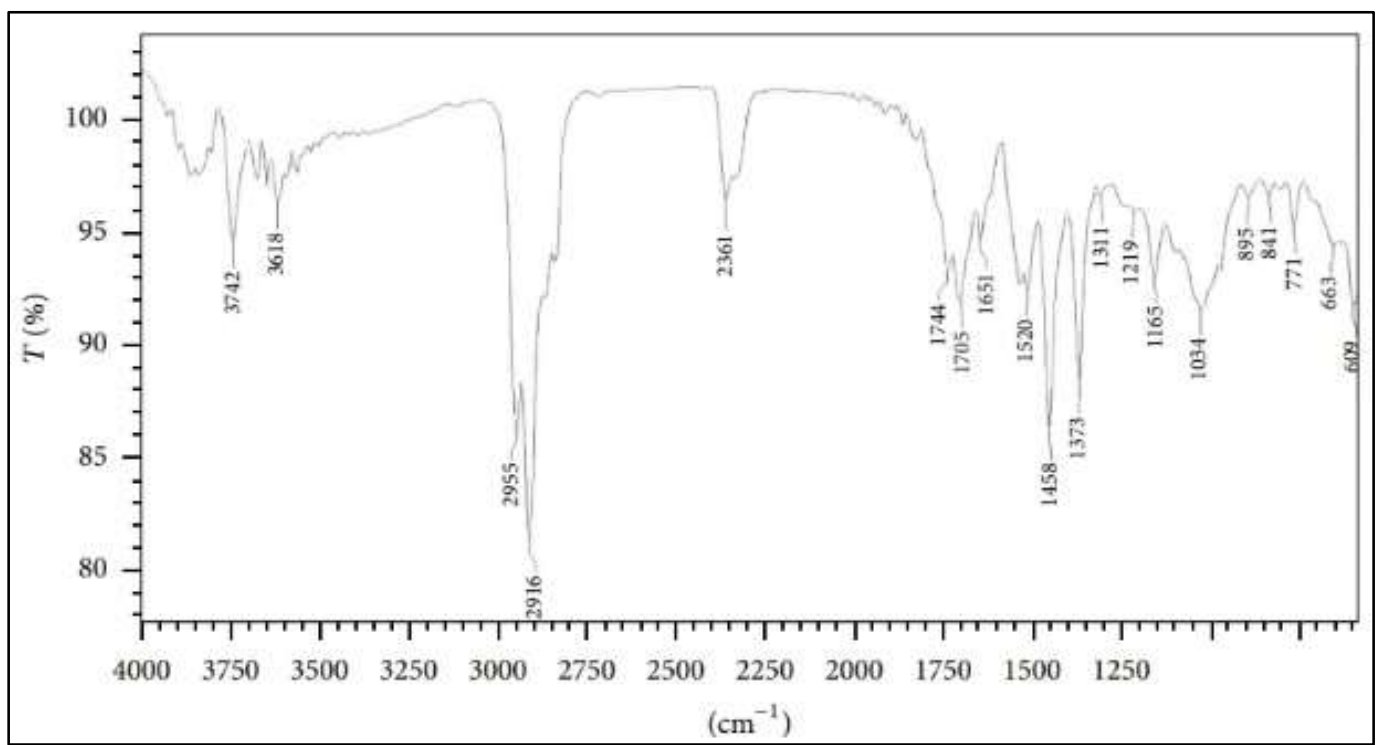

Fig. 6: GC-MS Analysis of extracted PHB

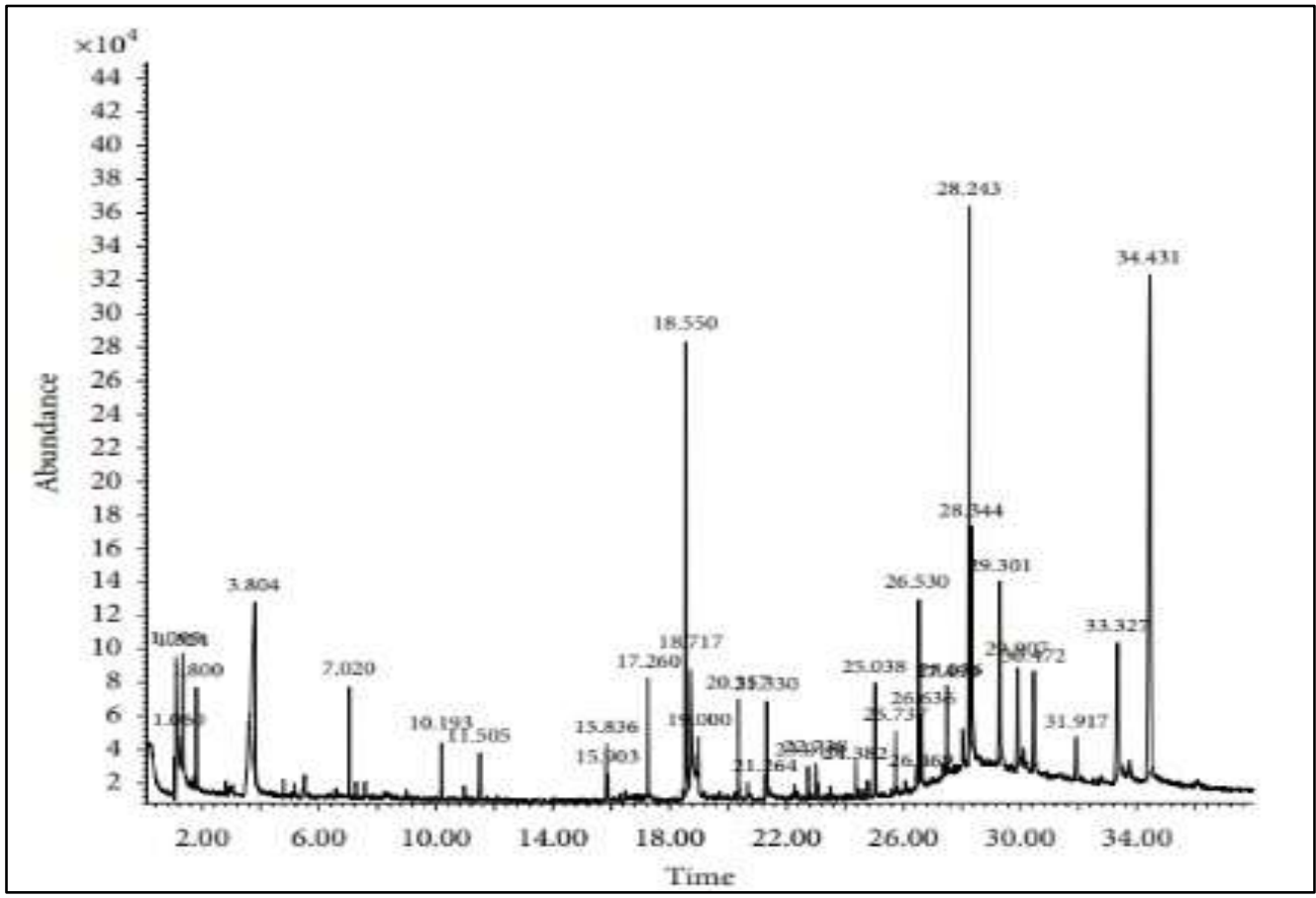


Fig. 7: Antibacterial activity of developed PHB film

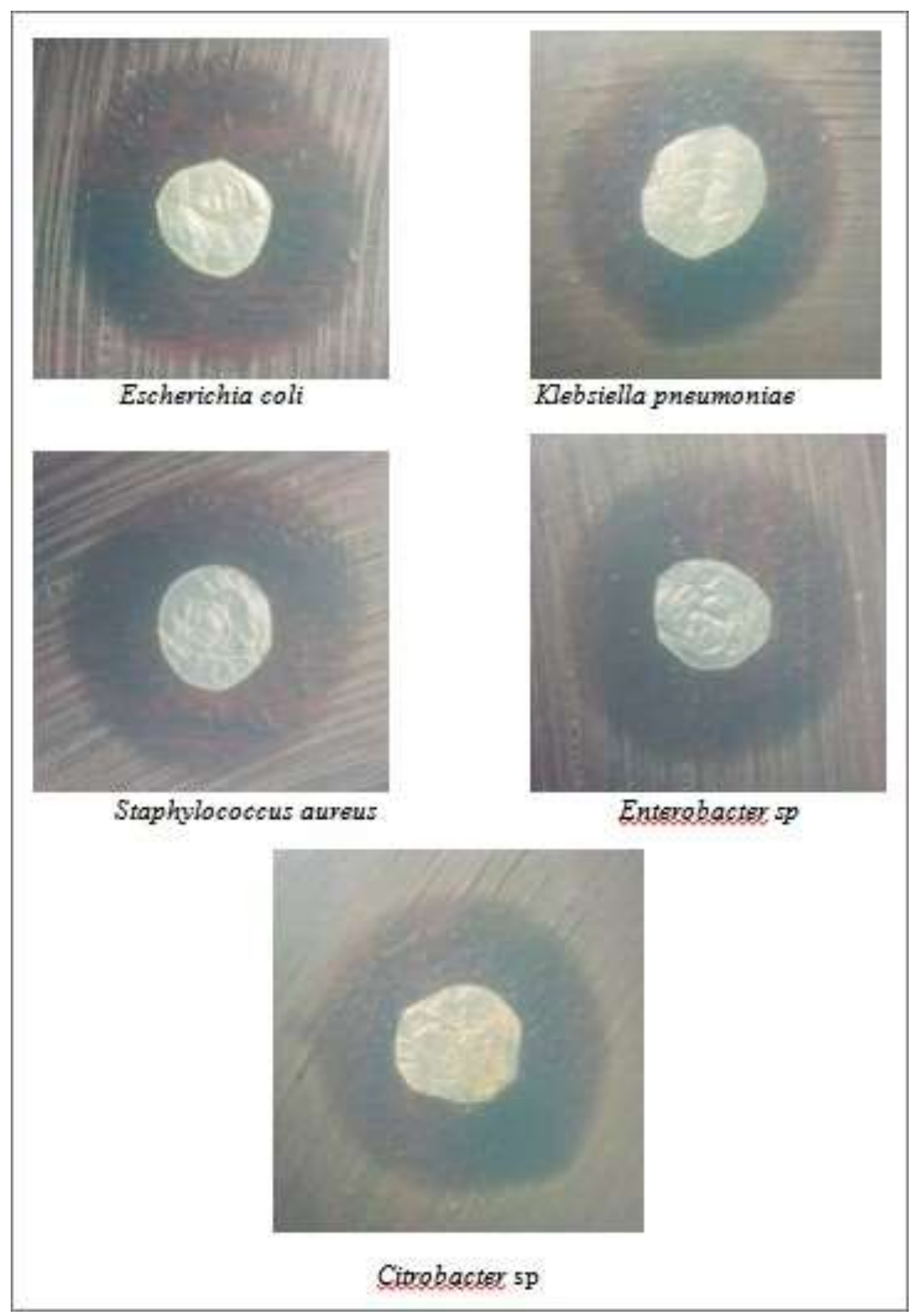

